\title{
KANT Y EL IDEALISMO ALEMÁN
}

\section{Introducción}

Voy a examinar la manera como la doctrina kantiana fue interpretada por aquellos pensadores a quienes la historia de la filosofía conoce como miembros del llamado Idealismo alemán. No trataré entonces de Kant, sino de la forma como sus doctrinas fueron comprendidas, analizadas, criticadas y transformadas, hasta verse convertidas en el punto de partida para proyectos filosóficos por completo ajenos e incluso contrarios a sus objetivos. Casi todos los historiadores de la filosofía señalan con extrañeza cómo, a partir de las duras críticas de Kant a la metafísica, se llevó a cabo lo que cabría interpretar como un proceso de poda al frondoso árbol de la especulación metafísica. En lugar de marchitarse, lo que vemos que sucedió fue un poderoso reverdecer con nuevas fuerzas, hasta el punto de que pocos periodos de la historia de las ideas pueden mostrarse tan fecundos en propuestas sistemáticas de la más atrevida especulación, como el de los 63 años que van desde la aparición de la Crítica de la razón pura (1781) hasta la muerte de Schelling, el último de los grandes idealistas (1854). 
Como bien lo expresa Frederick Copleston en su Historia de la filosofía:

Por una parte, la base filosófica inmediata del movimiento idealista le fue proporcionada por la filosofía crítica de Immanuel Kant, que se había enfrentado con las pretensiones de los metafísicos de proporcionar un conocimiento teórico sobre la realidad. Por otra parte, los idealistas alemanes se consideraban a sí mismos como los sucesores espirituales de Kant, y no simplemente como los que luchaban contra sus ideas. Lo que tenemos que explicar es cómo el idealismo metafísico pudo surgir del sistema de un pensador (como Kant), cuyo nombre ha quedado asociado para siempre con el escepticismo respecto a las pretensiones metafísicas de proporcionarnos un conocimiento teórico sobre la realidad como un todo. (Copleston, 1982, p. 16).

No cabría esperar que en el breve lapso de una exposición pudiera yo abarcar toda la diversa gama de interpretaciones a las que dio pie la filosofía crítica kantiana, ni siquiera si nos reducimos a los tres grandes pensadores del llamado Idealismo alemán: J. G. Fichte, F. Schelling y G. W. F. Hegel. Basta señalar que cada uno de ellos ofreció diversos intentos, algunos bastante diferenciados entre sí, de elaborar una alternativa filosófica que pudiera superar las insuficiencias o fallas que creía encontrar en el sistema kantiano. Refiriéndose a Fichte, nos dice Rolf-Peter Horstmann: "Dependiendo de cómo uno haga las cuentas, se pueden distinguir hasta 20 versiones diferentes de la Doctrina de la ciencia” (Horstmann 136, n. 7); y algo semejante puede decirse de Schelling.

Así que, en aras de la brevedad, y buscando apuntar a lo más significativo de esta interesante contraposición de puntos de vista y de métodos de reflexión filosófica, voy a centrar la atención en las propuestas filosóficas de Fichte y de Hegel, y ello por varias razones.

En primer lugar, porque constituyen, por así decirlo, los dos extremos del espectro: el primero, Fichte, buscando ser lo más fiel posible al pensamiento de Kant, y el otro, Hegel, apartándose claramente de él y buscando ofrecer una alternativa nueva y diferente. En otras palabras, si los miramos desde la perspectiva de su relación con la filosofía crítica, podríamos confirmar el orden en que se los suele considerar en las historias de la filosofía: Fichte el iniciador y Hegel el consumador del idealismo. Veremos, sin embargo, que este orden ha sido y está siendo cuestionado por no pocos intérpretes, con variadas razones que merecen toda nuestra consideración. 
Una segunda razón para escoger a esos dos pensadores es que Schelling, en lo que respecta a su crítica y distanciamiento con respecto a las doctrinas kantianas, comparte casi todos los puntos fundamentales con Hegel, distinguiéndose, sin embargo, y de manera muy significativa, en cuanto a las propuestas alternativas que cada uno presenta. Podríamos decir, en gracia de la brevedad, que mientras Fichte se propone consolidar la doctrina de Kant y extraer de ella algunas conclusiones que estima fundamentales, Schelling y Hegel buscan realmente superarla, señalando lo que consideran sus graves insuficiencias, su fallas fundamentales y la necesidad, por consiguiente, de avanzar por los nuevos horizontes a los que esa doctrina ha permitido acceder, pero que ella misma no solo no ha transitado, sino que, en cierta manera, impide recorrer.

Una tercera razón para centrar nuestra atención en esas dos figuras, Fichte y Hegel, tiene que ver con la forma tradicional como han sido interpretadas sus doctrinas, siguiendo indicaciones ofrecidas por el mismo Hegel. En esa visión tradicional se suele decir que mientras el idealismo de Fichte es subjetivo y el de Schelling objetivo, el de Hegel es absoluto, en el sentido muy hegeliano de que el primero, buscando encontrar el fundamento último y único de todo verdadero saber, pone el acento sobre el sujeto, mientras que el segundo lo hace sobre el objeto, mientras que Hegel lo hace sobre la síntesis dialéctica de ambos. No cabe duda alguna de que esta interpretación es en extremo esquemática, simplificadora, hasta el punto de ocultar elementos de la mayor significación en cada una de las tres propuestas para avanzar más allá de Kant. Es además sesgada, porque examina la relación entre los tres pensadores desde la perspectiva del último de ellos, Hegel. Pero creo que, a pesar de todo ello, sigue teniendo un doble valor que no cabe desconocer. El primero es que nos permite precisar, de manera simple y clara, los acentos que cada uno de estos pensadores se propuso otorgarle a su reflexión, sin entrar a examinar las consecuencias que tales acentos tienen sobre sus doctrinas. Mientras que Fichte se esfuerza por comprender la realidad de la libertad, y todo lo que ella puede significar para la vida del ser humano como individuo y como especie, Schelling pretende tomar muy en serio los avances del conocimiento científico en su comprensión del mundo y las consecuencias 
que del mismo se derivan para la reflexión filosófica; Hegel, por su parte, intenta integrar las dos propuestas anteriores, y propone una visión que, a la manera de Kant, trata de tener en cuenta las dos caras que presentan todos los problemas filosóficos fundamentales: la subjetiva y la objetiva, la sensible y la inteligible, la material y la espiritual, la formal y la del contenido, la necesaria y la contingente, la singular y la universal, y sobre todo la finita y la infinita.

Ahora bien, ese esquema simplificado con el que ha operado la tradición, y que podemos encontrar en intérpretes tan calificados como Nicolai Hartmann y Richard Kroner, no solamente nos permite apreciar mejor la estructura del pensamiento de cada uno de los tres pensadores, sino que también la historia de la influencia que cada uno de ellos ha logrado ejercer en la filosofía posterior pareciera corroborarlo en buena medida. Frente a Fichte y Schelling, no cabe duda de que ha sido Hegel el que mayor resonancia ha tenido en la historia posterior del pensamiento filosófico, y más allá de él. Y yo me atrevería a decir que esto sigue siendo cierto aun en nuestros días; porque, junto a la de Kant, la figura de Hegel continúa siendo hoy referente obligado en buena parte de las discusiones filosóficas.

Sin embargo, no podemos negar que los tiempos cambian y los intereses filosóficos también, de modo que hoy, cuando el tema de la libertad, por una parte, y el de la estética, por el otro, así como la preocupación por los límites del pensar racional, han venido siendo objeto de creciente preocupación filosófica, bien cabe esperar que las figuras de Fichte y de Schelling recobren cada vez mayor interés, y no faltan quienes señalan que ese orden tradicional, en el que pareciera darse una línea continua y ascendente que parte de Fichte y se eleva hasta llegar a Hegel, debe ser revisado para cambiar el orden de los factores y colocar, ya sea a Fichte, ya sea a Schelling, en la verdadera cima del idealismo alemán, o para cuestionar la misma idea de una línea continua y ascendente, viendo más bien cómo cada uno de ellos ha seguido su propio camino, obedeciendo a intereses diversos y ofreciendo alternativas diferentes.

Existe una cuarta razón para reducir mi consideración a las filosofías de Fichte y Hegel, y es la necesidad de detenernos un momento a considerar algunos de los antecedentes de la aparición del idealismo, sin los cuales resulta difícil entender su, en apariencia, inesperado surgimiento. Se trata 
de establecer una "composición de lugar", y de señalar aquellos elementos básicos que orientaron la discusión y la condujeron hasta desembocar en las propuestas idealistas. Debo confesar que, personalmente, comencé a comprender en verdad el significado profundo de las doctrinas kantianas, cuando tuve ocasión de examinar las discusiones que ellas suscitaron en el ámbito del pensamiento alemán. Libros como los de Nicolai Hartmann, Ernst Cassirer, Richard Kroner y, entre nosotros, el de Luis Eduardo Hoyos, conforman un camino expedito para evaluar el significado del kantismo en la historia del pensamiento occidental.

Así que mi exposición tendrá tres partes. En la primera, busco examinar el contexto de las discusiones a las que dio lugar la filosofía crítica de Kant, contexto que sirve de suelo abonado para el surgimiento de las propuestas idealistas; en la segunda, examinaré las líneas fundamentales de la filosofía de Fichte en su propósito de desarrollar la novedad del kantismo; y en la tercera, expondré las críticas de Hegel al kantismo y su intento de avanzar por nuevos caminos. Presentaré, al final, algunas consideraciones generales acerca del significado que pueda seguir teniendo el idealismo en nuestra época, designada por algunos como post- o antimetafísica.

\section{La discusión sobre la filosofía crítica}

Para comprender la discusión que se tejió alrededor de las tesis kantianas, y a la que algunos han bautizado con el nombre de "querella sobre la cosa en sí", vale la pena comenzar señalando lo que nos dice Luis Eduardo Hoyos en su estudio sobre los antecedentes escépticos del Idealismo alemán, al referirse al primer gran intérprete de Kant, quien sin duda jugó un papel decisivo en la difusión de su doctrina, Karl Leonhard Reinhold. Hoyos escribe: "Si un calificativo merece la filosofía trascendental kantiana, con respecto al cual podrían ponerse de acuerdo los más notables de sus intérpretes y críticos, este es -además del de oscura y difícil de comprenderel calificativo de aporética" (Hoyos, 2001, p. 25).

Si consultamos en el Diccionario de la Real Academia lo que se quiere significar con el término aporía, podemos leer: "del griego áporía, dificultad de pasar. En filosofía, enunciado que expresa o que contiene una inviabilidad de orden racional”. En otras palabras, la doctrina kantiana 
resulta ser un manjar filosófico de muy difícil digestión, y esto llevó a sus intérpretes y críticos a ensayar toda suerte de lances para buscar, ya sea salvar lo que consideraban sus grandes logros, ya sea destruir sus pretensiones o corregir sus insuficiencias. Pero lo más interesante del asunto está en que su primer gran comentarista, en el sentido de haberlo hecho conocer y haber despertado el interés por su obra, Reinhold, se tomó muy en serio aquello de que la filosofía kantiana no era más que "prolegómenos a toda metafísica futura que pretenda presentarse como ciencia”, como llamó Kant a su pequeño escrito en el que buscaba resumir su Crítica de la razón pura. Es decir que, a los ojos de Kant, lo ofrecido en esa obra eran solo las condiciones que deberían cumplirse para poder desarrollar una verdadera metafísica que respondiera a las exigencias de una cuidadosa crítica de nuestra facultad cognoscitiva. Y, animado por ello, Reinhold consideró necesario desarrollar el plan propuesto por el maestro y buscarle un nuevo fundamento a esa filosofía del futuro, porque, a su parecer, Kant no lo había hecho. Las tesis del criticismo son válidas, pensaba Reinhold, pero su fundamentación resulta insuficiente y ello las hace vulnerables a la crítica escéptica.

Con ello estaba planteando la primera gran pregunta a la que dará pie la filosofía crítica, y que orientará en gran medida su interpretación: ¿es posible encontrar un fundamento último y definitivo para nuestro conocimiento? Pregunta que ya se había hecho Descartes, como todos ellos bien lo sabían, pero que era necesario volver a examinar bajo las nuevas condiciones establecidas por los análisis kantianos. Porque si ese fundamento último no podía encontrarse, no cabía esperar una respuesta satisfactoria a la pregunta que había hecho el escepticismo: ¿podemos aspirar a conocimientos universales y necesarios, dado que nuestra facultad de conocer se halla condicionada, en su misma raíz, por la experiencia sensible que solo nos ofrece casos singulares, experiencias únicas e irrepetibles?

A esta pregunta, Kant creía haber dado una respuesta satisfactoria, al menos hasta donde podíamos esperar hacerlo, y la respuesta tenía una inquietante similitud con la que había dado Descartes exactamente 140 años atrás: nuestro conocimiento es muy limitado, pero dentro de esos límites podemos llegar a formular aserciones indudables, universales y necesarias. Sin embargo, la diferencia entre el pensador francés y el alemán era de la mayor importancia. Porque mientras que Descartes creía haber 
asegurado que tales aserciones tenían validez para las cosas tal como son en sí mismas, gracias a que un Dios veraz se encargaba de garantizarlas, Kant ya no estaba en condiciones de contar con ese aval divino. No olvidemos que la prueba de la existencia de un Dios veraz que lleva a cabo Descartes en su Tercera Meditación cae inevitablemente en un círculo vicioso. Era necesario apoyar el valor objetivo del pensamiento racional en la estructura misma del conocimiento, y ese apoyo, al parecer de Kant, solo alcanzaba para salvar los fenómenos, es decir, la forma como esa realidad se nos hace presente, pero no nos permite estar seguros de que las cosas en sí mismas sean y tengan que ser tal y como nosotros las comprendemos.

Ahora bien, el problema se hizo acuciante cuando, en 1792, apareció la obra de Gottlob Ernst Schulze, titulada de manera muy significativa, y hasta diríamos que provocadora: Aenesidemus, o acerca de los fundamentos de la filosofía elemental ofrecidos por el Señor Profesor Reinhold en Jena. Junto con una defensa del escepticismo en contra de las osadías de la crítica de la razón. Enesidemo había sido un filósofo griego, discípulo de Heráclito, por los años 50 antes de Cristo, que había restaurado la escuela escéptica de Pirrón y escrito seis libros sobre filosofía escéptica. El propósito de la obra de Schulze era mostrar cómo los argumentos kantianos no habían podido responder de manera satisfactoria a las objeciones del escepticismo, y esto resultaba aún más claro cuando se analizaba la interpretación que de ellos había hecho Reinhold. "El escepticismo de Schulze consiste principalmente -nos dice Luis Eduardo Hoyos- en mostrar la insuficiencia de la filosofía especulativa del conocimiento en su pretensión de determinar el fundamento último de este" (Hoyos, 2001, p. 124). En otras palabras, dada la radical diferencia entre el sujeto que conoce y los objetos que conoce, no cabe esperar que el sujeto mismo, a partir de su propia estructura cognoscitiva, pueda garantizar que su conocimiento acerca del mundo corresponda plenamente con lo que ese mundo es en sí mismo.

Tal vez lo más significativo del escepticismo de Schulze, examinado desde la perspectiva de la historia de las ideas, es que sirvió de acicate para que un kantiano convencido, como lo fue precisamente Fichte, viera sus convicciones profundamente resquebrajadas y se sintiera obligado a repensar a fondo la filosofía crítica. Sobre esto volveré, cuando entre a examinar la doctrina de Fichte. 
Ahora bien, si los fundamentos últimos del conocimiento resultaban cuestionados, y ello implicaba una gran debilidad frente a los ataques del escepticismo, este problema se hallaba íntimamente ligado con una segunda pregunta que cabía hacerle al kantismo, la que, en cierto sentido, era de mayor envergadura y de mayor calado que la primera: ¿podemos llegar a saber con suficiente certeza que existen realidades o que existe una realidad que esté más allá de los sentidos? Es decir ¿existe un mundo suprasensible?; ¿o tenemos que atenernos exclusivamente al mundo material, regido por la más férrea ley de la necesidad causal? Si el primer problema, el del escepticismo, minaba las aparentes seguridades del sentido común al llevarnos a pensar que la realidad en sí misma era, o al menos podía ser, muy diferente a como se nos muestra, inclusive a como se le presenta al conocimiento científico; el segundo problema, el del materialismo, llegaba hasta poner en cuestión la existencia de la libertad y la inmortalidad del alma, y con ello, por supuesto, la existencia de un Dios, al menos de uno tal como lo ha predicado la tradición cristiana, es decir, de un Dios personal.

Como lo señala muy bien Frederick Beiser en su ensayo sobre la relación entre la Ilustración y el Idealismo, la doctrina kantiana había puesto en cuestión la raíz misma del proyecto ilustrado, a saber, la confianza irrestricta en los alcances de nuestra razón para explicarnos el mundo y orientar nuestro comportamiento. Pero había cuestionado esa confianza en la razón sin pretender renunciar a ella, estableciendo toda una serie de distinciones inevitables, pero también problemáticas, entre sensibilidad y entendimiento, entre razón teórica y razón práctica, entre fenómeno y noúmeno, etc. El idealismo, entonces, en manos de Fichte, asume la doble tarea de salvar al criticismo de caer en el escepticismo, por una parte, y al naturalismo científico de caer en un craso materialismo, por la otra; pero lo hace tratando de mantener incólume lo que, al igual que Kant, considera ser el legado irrenunciable de la propuesta ilustrada, a saber, su confianza en las fuerzas de nuestra propia razón. Ahora bien, el problema consistía en que esa crisis parecía ser, precisamente, la consecuencia inevitable de haber confiado por completo en la razón, porque era la razón misma la que nos llevaba, de manera irremediable, a naufragar frente a esos dos escollos: el escepticismo y el materialismo. 
En realidad, la Ilustración operaba con dos conceptos diferentes de razón: uno negativo, que la caracterizaba por sus capacidad de someter a crítica y destruir todas las evidencias aparentes, y uno positivo, según el cual es la razón la que nos ofrece la explicación de los fenómenos al considerarlos como casos de leyes generales. Pero, al llevar al límite ambos conceptos, desembocaba irremediablemente en el escepticismo, por un lado, y en el materialismo, por el otro. Si el escepticismo es el resultado inevitable del empeño iniciado por Descartes de fundamentar la razón por sí misma, la reducción naturalista del conocimiento al ámbito de lo sensible, por su parte, implica que todo lo cognoscible puede ser explicado por leyes mecánicas, es decir, aquellas que rigen para lo cuantificable, para lo exclusivamente material. Y lo que era peor aún, escepticismo y materialismo, llevados hasta sus límites, terminaban por destruirse, porque un escepticismo radical no nos permite hablar con certeza sobre la configuración de la realidad exterior a nuestro pensamiento, no nos permite decir, con plena certeza, que el mundo no sea más que materia.

Esto me obliga a considerar, aunque sea en forma muy somera, otra de las figuras que precedieron la aparición de los sistemas idealistas, y cuyo papel en las controversias que suscitó la obra kantiana fue de los más significativos: Friedrich Heinrich Jacobi. De él nos dice Cassirer que

[...] tuvo el singular destino de lanzar siempre y en todas partes a la palestra fuerzas superiores a las suyas, y de señalar caminos cuya estación de llegada y cuya meta no alcanzaba por sí mismo a prever. Y lo mismo exactamente puede decirse con respecto al papel que a Jacobi le estaba reservado en la historia y la trayectoria ulterior de las doctrinas kantianas. También aquí vemos cómo plantea, con brillante sagacidad, nuevos problemas, y avizora dificultades llamadas a determinar por largo tiempo la forma de la filosofía; sin embargo, las soluciones dadas por él a estos problemas tuvieron siempre una existencia histórica aparente y fugaz. (Cassirer, 1957, p. 32).

A Jacobi se lo considera, siguiendo la imagen de Platón con respecto a Sócrates, como el "tábano" de su época, y sus agudas intervenciones dieron lugar a las tres más grandes y significativas controversias de la Alemania de entonces: la del spinocismo de Lessing, la del ateísmo de Fichte y la del panteísmo de Schelling. No puedo detenerme a examinar estas 
controversias, cuyo papel en el surgimiento de las doctrinas idealistas fue, sin duda, muy significativo. Solo hago mención de ellas para encuadrar la figura de Jacobi, y para tratar de comprender, a grandes rasgos, el carácter de sus críticas y el sentido de sus propuestas alternativas.

No cabría decir que Jacobi haya sido un antikantiano, como tampoco que hubiera sido un antispinocista. Tal vez sería más correcto decir que su conocimiento de Spinoza y de Kant lo llevaron a convencerse de que ambos sistemas de pensamiento, por su consecuente racionalismo, mostraban precisamente cómo la razón no puede menos de conducirnos al materialismo y al escepticismo. Aunque la formulación pueda sonar paradójica, Paul Franks nos dice, con razón, que al proyecto de Jacobi cabría caracterizarlo mejor como una "defensa de la razón contra el racionalismo" (Franks, 2000, p. 95).

La tesis fundamental de Jacobi podríamos resumirla así: ofrecer una justificación racional significa descubrir las razones o los principios de algo; ahora bien, un fundamento absoluto o incondicionado, tanto epistemológico como ontológico, tendría que ser algo que por su misma naturaleza no tuviera ni razones ni principios; luego un principio absoluto, ya sea del conocimiento, ya sea de la realidad, no puede ser justificado racionalmente. Este argumento conviene leerlo en el contexto de una profunda experiencia personal vivida por Jacobi cuando tenía la edad de nueve años, en la cual se llenó de angustia ante la idea de la infinitud; experiencia que, como en el caso de muchos otros filósofos, hizo tambalear todas sus convicciones, y lo llevó a buscar encarnizadamente un punto de apoyo firme para las mismas. Es interesante señalar que su primera obra publicada llevaba como encabezamiento la sentencia griega: dos moi pou sto (dadme un punto de apoyo, dame un punto donde pueda pararme). Sentencia que ya había utilizado Descartes en sus Meditaciones, refiriéndose a Arquímedes, y que había orientado en buena medida la búsqueda platónica ${ }^{41}$.

La gravedad del asunto no se reducía al hecho de que toda justificación última resultara imposible, sino que ello mismo conducía, al parecer de Jacobi, a cuatro consecuencias inaceptables para sus más profundas convicciones tanto racionales como religiosas: al monismo, al ateísmo, al

41 Sobre la búsqueda de un punto firme por parte de Platón, puede leerse el hermoso texto de Juan David García Bacca: "Platón: modelo de método trascendental simbólico de filosofar" (1979, pp. 11-42). 
fatalismo y al nihilismo. Sin que entremos a examinar sus argumentos para cada una de estas afirmaciones, por lo demás no siempre muy claros, pero que lograron, sí, un gran impacto entre los filósofos de su entorno, digamos que la alternativa que ofrece Jacobi es la de un salto mortal a la fe, una decisión de la voluntad para aceptar como incuestionable la idea de un Dios trascendente, personal y providente. Esta decisión debería tomarse, por decirlo así, "al margen de la razón", porque intentar justificarla, o intentar invalidar los argumentos del racionalismo, era caer en sus redes. Se trataba entonces de cambiar de modo de ver el mundo, de llevar a cabo una conversión (metanoia) en cuanto a la manera de vivir, muy semejante, a mi parecer, a la manera como entendió Ludwig Wittgenstein el sentido de la fe religiosa.

Tenemos entonces que la controversia despertada por la obra de Kant había ido centrándose en dos puntos fundamentales, íntimamente ligados entre sí, y cada uno de los cuales tenía implicaciones de gran envergadura: 1) ¿Es posible fundamentar de manera absolutamente incuestionable nuestro conocimiento de la realidad exterior? 2) ¿Hay argumentos que justifiquen la existencia de una realidad suprasensible? El primero tiene un carácter epistemológico y el segundo un carácter ontológico y ético. Pero su conexión resulta clara, porque si no podemos conocer con seguridad cómo es nuestro mundo circundante, menos aún podemos hacerlo con respecto a un mundo suprasensible; y si tenemos que atenernos únicamente al mundo sensible que nos rodea, este solo podemos concebirlo como sometido a una férrea necesidad mecánica y la libertad no parece posible.

Por ello, Kant había buscado un acceso racional a ese mundo no sensible, pero un acceso no cognoscitivo, sino práctico. ¿Lo había realmente logrado?, ¿qué consecuencias tenían sus doctrinas? Una vez planteado en estos términos el problema de interpretar la filosofía crítica kantiana, es posible entender mejor la respuesta que buscará Fichte a esos interrogantes.

\section{Fichte o la filosofía de la libertad}

Es importante, cuando se busca entender la respuesta que ofrece Fichte a los interrogantes que planteaba la filosofía crítica de Kant, tener muy en cuenta tres elementos: 1) que su pretensión no fue criticar a Kant, sino 
aprovechar sus aportes, buscando consolidar sus fundamentos y deducir algunas conclusiones que consideraba de la mayor importancia; 2) que su preocupación fundamental, en lo cual concordaba en buena medida con Kant, era cómo salvaguardar la libertad humana, que se veía amenazada por la concepción científica de un mundo regido por la férrea ley de la causalidad mecánica; 3) que la respuesta que dará a esas preguntas es eminentemente ética, más que epistemológica o metafísica.

Fichte comenzó por encontrar en Kant la solución a una preocupación que lo acuciaba profundamente: ¿cómo es posible la libertad humana si el mundo se halla regido por las leyes inflexibles de la necesidad causal? El problema había sido planteado claramente tanto por Leibniz, como sobre todo por Spinoza, cuando uno y otro mostraron que una visión racional del mundo conducía de manera indefectible al más duro determinismo, que parecía desembocar de manera inevitable en el fatalismo. La libertad humana no sería entonces más que una vana ilusión, producto de la ignorancia, y la filosofía tenía entonces, como una de sus funciones primordiales, liberarnos de esa ilusión.

Pero si Kant parecía ofrecer una solución al problema, su argumentación, como lo había indicado Reinhold, carecía de una sólida fundamentación, porque partía de un dualismo radical entre el sujeto que conoce y el mundo conocido que daba pie a los argumentos escépticos, echando así por tierra su demostración. Todo conocimiento se mostraba como radicalmente condicionado, ya que dependía de que lo dado se dé, de que lo conocido se nos haga presente. Había entonces que buscarle un fundamento último al conocimiento que fuera inmune a los ataques escépticos, y este fundamento estaba en la estructura misma de la conciencia humana como condición de todo conocimiento posible. La famosa "proposición o principio de la conciencia", que proponía Reinhold como fundamento último de todo conocimiento, decía que la conciencia, en su acto de conocer, distingue y relaciona a la vez al sujeto que conoce, al objeto conocido y al acto mediante el cual se lo conoce. Gracias a ese principio fundamental, cuyo conocimiento se halla implícito en todo acto de conocer, cabe entender que los objetos no son algo simplemente dado, algo que está ahí y se nos hace presente imponiéndonos sus condiciones, por así decirlo. Sino que el objeto es la contrapartida del sujeto, el resultado del acto mediante el cual el sujeto, al volver sobre sí y distinguirse del mundo, distingue a su vez ese mundo de sí mismo y lo pone ante él. 
Pero con la crítica de Schulze en el Aenesidemus, Fichte tuvo que aceptar que ese principio no podía ser el primero y fundamental, porque estaba condicionado por un acto de reflexión para el cual era necesaria la presencia de un objeto, es decir, que el principio de la conciencia resultaba tan condicionado como el yo pienso cartesiano que, como decía Kant, debe poder acompañar a todas nuestras representaciones. Ahora bien, como renunciar a un principio último de unidad significaba concederle la razón al escepticismo, había que buscar ese principio a sabiendas de que tenía que existir.

Dieter Henrich nos explica muy bien cómo, buscando superar el dualismo kantiano, llegó Fichte a su doctrina del Yo absoluto como fundamento unitario de todo conocimiento:

Si partimos de la forma más temprana de la Doctrina de la ciencia, [...] se puede ver que Fichte llegó a su teoría gracias a dos descubrimientos que se sucedieron en corto tiempo: primero comprendió, contra la tesis de Reinhold, que el acto fundamental de la conciencia no puede ser un relacionar y distinguir. Previo a esto tiene que darse un oponer que brinde las posibilidades de distinguir. La tesis de Fichte más rica en consecuencias es que la conciencia solo es comprensible a partir de la oposición, y no a partir del enlace de lo múltiple, como decía Kant. En un segundo paso, comprendió Fichte igualmente que la oposición, por su parte, exigía también un fundamento de unidad. No pudo encontrarlo sino en el carácter absoluto de la autoconciencia que abarca toda oposición. (Henrich, 1987, p. 19).

Tal vez para comprender mejor la idea de Fichte sea bueno tener en cuenta algo que se halla presente en toda su argumentación, así como en la argumentación de Reinhold y de sus contemporáneos, pero que no suele hacerse patente en sus maneras de argumentar. Se trata de algo que Spinoza había visto con toda claridad, pero que tampoco él había sentido la necesidad de formular de manera expresa. Y es que el problema fundamental que distancia a los escépticos o empiristas de los racionalistas o idealistas está en la cuestión de si es posible en alguna forma pasar del pensamiento al ser, es decir, si es posible, a partir de conceptos, llegar por deducción lógica o por otro medio a una afirmación de realidad. Partiendo de la radical diferencia cartesiana entre el mundo interior de la conciencia 
y el mundo exterior a ella, y de que lo único a lo que tenemos acceso privilegiado es a nuestro mundo consciente, cabe entonces preguntarse: ¿es posible encontrar un acceso desde el mundo de la conciencia o mundo de los conceptos al mundo exterior o mundo propiamente real?

La respuesta de Spinoza había sido simple, pero profundamente peligrosa: existe un acceso desde el pensamiento a la realidad y este se halla en el concepto adecuado de sustancia. La primera parte de su Ética no se propone otra cosa que mostrarlo y sacar de ello las consecuencias. Pero, precisamente, eran esas consecuencias las que resultaban inadmisibles para quienes no estaban dispuestos a aceptar su peculiar concepción de libertad, ni su peculiar concepción de Dios. Una sustancia omnienvolvente, dentro de la cual el sujeto humano no viene a ser más que un modo, un momento pasajero de la misma, sometido por completo a su necesidad implacable, no permite pensar una verdadera libertad como autodeterminación, como autoconstitución o autonomía. Había entonces que buscar otro camino, y este no parecía posible, si se quería salvaguardar la libertad, sino a través del mismo sujeto cognoscente. En esto Reinhold tenía razón, pero no la tenía al considerar que el principio se hallaba en la conciencia como síntesis o relación de tres momentos diferentes, el sujeto mismo, el objeto y el acto, porque ello suponía, como lo señalaba Schulze, la presencia de algo ajeno a la conciencia que diera pie a su reflexión.

Para superar este escollo, Fichte va a ensayar dos maniobras simultáneas. Por una parte, profundizar en esa conciencia para encontrar en ella un fundamento más original, que sería el puro yo como presencia inmediata a sí mismo. Se trata de recuperar un elemento fundamental del cogito cartesiano, ya que en el acto mismo de ser consciente de sí, el pensamiento es consciente de su misma existencia y de no poder estar errado en cuanto a ello; en otras palabras, el pensamiento que sabe de sí está en condiciones de ofrecer una afirmación de existencia, está en condiciones de pasar correctamente del pensamiento al ser. Pero se trataba del ser del pensamiento y, además, como ya Descartes lo había constatado, ese cogito era una realidad demasiado precaria como para servir de fundamento inconmovible, porque solo era tal mientras se la pensaba; de modo que se vio en la necesidad de acudir a Dios en busca de apoyo.

Para Fichte, el acceso a Dios estaba doblemente vedado. Por una parte, 
la argumentación cartesiana para demostrar la existencia del Dios veraz resultaba errónea, porque caía, como bien sabemos, en un círculo vicioso. Y, por otra, la tarea que había que realizar, siguiendo las indicaciones de Kant, consistía en buscar en el conocimiento mismo su propio fundamento. Así que ello llevó a que Fichte emprendiera la segunda maniobra, aprendida del mismo Kant, y que consiste en considerar a ese Yo absoluto o incondicionado no como un fundamento originario propiamente tal, sino como una idea reguladora, como una meta inalcanzable que sirve de orientación. ¿Qué significa esto? Que se trata de considerar la realidad, no como una sustancia, sino como un Yo, como una realidad que por sí misma se desdobla y pone su otro como un momento de sí misma; pero ese Yo no es algo dado, algo que está ahí previamente, sino una idea reguladora, es decir, una meta bajo cuya orientación debemos realizar todas nuestras acciones conscientes, comenzando, claro está, por nuestros conocimientos.

Tal vez podamos comprender mejor el sentido de esa doble maniobra, si la consideramos desde otra perspectiva. La idea de un conocimiento absolutamente cierto, es decir, del cual no quepa la menor duda, implica la total identidad entre el sujeto que conoce y el objeto conocido, de modo que todo conocimiento que se pretenda verdadero debe aspirar a esa identidad. Ahora bien, el modelo de esa identidad es precisamente el Yo, que, al saberse a sí mismo, identifica al sujeto que conoce con el objeto conocido y con el acto de conocerlo. Esto significa que si pretendemos comprender la realidad de manera absoluta, es decir, incondicionada, tendríamos que pensarla como un Yo, que no sería por supuesto el yo humano, sino un Yo absoluto, incondicionado, trascendental, en el sentido de condición de posibilidad de todo conocimiento. Pero ese yo no es un hecho dado, ni una evidencia a la que tengamos acceso, sino una meta, un "como si", una idea reguladora. Y esa idea reguladora juega un doble papel que podemos considerar tanto epistemológico como ético. Sirve, en primer lugar, de paradigma para todo conocimiento, en la medida en que conocer la realidad es tratarla como si fuera la expresión o la manifestación de un Yo incondicionado, de un devenir que, saliendo de sí mismo, se vuelve sobre sí para descubrir su propio ser, para saber de su propia estructura racional. Y sirve también, en segundo lugar, de paradigma para nuestro obrar racional, porque se trata de convertir ese mundo dado en un Yo, es decir, en una 
estructura racional auto-transparente. El Yo absoluto no es entonces para Fichte una realidad dada, sino la meta del "impulso" en el que consiste el yo finito, el yo humano; "impulso" que el deber de conformar la Naturaleza a las exigencias de la razón.

Los beneficios que reportaba esa doble maniobra eran muy significativos. Por una parte, se le daba al conocimiento un fundamento absoluto, inmune al escepticismo, en la medida en que se hacía notar que todo conocimiento racional opera necesariamente bajo el supuesto de que la realidad dada no puede ser otra cosa que la expresión de ese Yo trascendental, incondicionado. No se trata de demostrar que ese Yo exista de hecho, sino que se lo considera como la meta inevitable, necesaria, de todo nuestro comportamiento racional. Por otra parte, se lograba superar el peligroso dualismo kantiano entre lo cognoscitivo y lo ético, porque ahora se los comprende, no como dos ámbitos heterogéneos en los cuales vive el ser humano en cuanto ser racional, tal como aparecían en Kant, sino como las dos caras de la misma realidad, la cognoscitiva y la práctica. Porque comprender la realidad como un Yo es comprenderla como una tarea que consiste en descubrir sus estructuras racionales y utilizarlas para racionalizar a su vez lo que esa realidad tiene aún de no racional, de simplemente dado, de sensible. Tarea infinita, es verdad, pero que le otorga el carácter racional al ser humano, al salvaguardar su libertad, la que no aparece ahora como una entidad aparte de la realidad dada, sino como la tarea de convertir esa realidad dada en una realidad racional.

Frederick Beiser nos hace el siguiente comentario:

A pesar de su brillantez la Doctrina de la ciencia tuvo una vida breve. Como un cohete, se elevó rápidamente a las alturas, pero solo para explotar en el aire. A los jóvenes románticos -Hölderlin, Schelling y Hegel, Novalis, Schlegel y Hülsen- los impresionó mucho Fichte, cuyas lecciones algunos de ellos habían escuchado en Jena en 1795. Pero tan pronto como escucharon al 'titán de Jena', empezaron a torpedearlo. Ya en el invierno de 1796, Hölderlin, Novalis y Schlegel comenzaron a llenar sus cuadernos de notas con críticas al idealismo de Fichte. Es en estos cuadernos de notas donde podemos trazar los comienzos del idealismo absoluto (Beiser, 2000, p. 31).

La deuda que hayan tenido tanto Schelling como Hegel con respecto 
a su común amigo Hölderlin, es hoy objeto de múltiples análisis y comentarios. No ha faltado quien sostenga que el verdadero pensador original entre los tres compañeros del Convictorio de Tubinga es el poeta. Pero sea de ello lo que fuere, el impulso recibido de Hölderlin fue el que llevó a Hegel a apartarse definitivamente de Kant y a elaborar su propio sistema filosófico. "Antes de su encuentro con Hölderlin en Frankfurt nos dice Dieter Henrich-, Hegel era un crítico de la Iglesia y un analista de las circunstancias históricas y políticas, aliado de la Gironde. Por su encuentro y por su rechazo de Hölderlin se convirtió en el filósofo de su época” (Henrich, 1987, p. 32).

\section{Hegel o el monismo incondicionado}

Voy a comenzar esta tercera parte de mi exposición con una larga cita de RolfPeter Horstmann acerca de la crítica que le hace Hegel a la propuesta filosófica de Kant, porque nos sirve de guía para lo que desarrollaremos a continuación:

La crítica de Hegel a la filosofía kantiana es, como se sabe, tan general como fundamental. Es una crítica general, en el sentido de que no hay ningún ámbito de la filosofía de Kant que no haya sido criticado por Hegel. [...] De otro lado, la crítica de Hegel a la empresa filosófica kantiana es fundamental, en el sentido en que no se contenta con plantear objeciones inmanentes contra algunas de sus afirmaciones, es decir, con cuestionar las tesis de Kant en el marco de los presupuestos de su propia filosofía. Lo que a Hegel le interesa es más bien demostrar que Kant está condenado al fracaso al sostener aquellas tesis, no simplemente porque éstas carezcan de sostén en sus propios principios, sino porque los principios mismos que él asume no pueden sino fracasar. La crítica de Hegel a Kant es por eso crítica de principio, lo que equivale a decir que es una crítica del carácter fundamentalmente engañoso de su visión filosófica del mundo. (Horstmann, 2003, p. 137).

Esta formulación puede resultarnos un tanto extraña, si recordamos la manera como Hegel comprende la historia de la filosofía, en la que cada sistema filosófico que alcanza el nivel de filosofía universal -y la filosofía crítica de Kant alcanza sin duda ese nivel- es la traducción de su época a conceptos, y en esa medida es verdadera. Pero ello no quita, sino que, por el contrario, explica y justifica que, al estar condicionada por su momento 
histórico, deba ser superada, es decir, haya que descubrirle sus limitaciones y la necesidad de ir más allá de ella. Y Hegel se proponía, nada más y nada menos, que llevar a cabo una crítica radical al pensamiento que había orientado el proyecto filosófico moderno a partir de Descartes, porque consideraba que, habiendo llegado a su plenitud con la filosofía de Kant, ofrecía las condiciones para su real superación.

Es en este contexto donde conviene situar las críticas que Hegel hace al proyecto filosófico kantiano, en el cual encuentra la plena realización del ideal que ha conducido la época moderna, y que bien cabría resumir, con todo el peligro que un resumen pueda tener, diciendo que tal ideal era la libertad del individuo como tal. Esto explica que viera en la filosofía de Fichte un instrumento muy adecuado para lograr esa superación.

No hay lugar en esta exposición para analizar las interesantes y complejas relaciones que cabe establecer entre la filosofía de Hegel y las de sus contemporáneos: Fichte, Hölderlin y Schelling. Digamos únicamente que, si bien Hölderlin le dio el impulso a Hegel para tomar distancia de Kant y le indicó igualmente la insuficiencia de la propuesta alternativa de Fichte, fue a su vez la filosofía de Fichte la que le permitió a Hegel tomar distancia de Hölderlin y elaborar así su propio sistema, apoyado en sus inicios por su colega Schelling, y apartándose luego de él. Este último distanciamiento proviene del fuerte irracionalismo romántico que percibe Hegel en la doctrina schellinguiana de la identidad, y frente al cual Hegel prefiere apoyarse en el austero racionalismo de Spinoza.

Voy a intentar traducir esto a un lenguaje propiamente conceptual. Para ello conviene recordar que el problema fundamental, dejado en herencia por la filosofía crítica kantiana, era, para los idealistas, su profundo dualismo, es decir, toda una lista de dualidades insalvables que ponían en peligro no solamente el propósito de un saber seguro y fundamentado, sino también la fundamentación de una ética racional llena de contenido. El origen de ese profundo dualismo creían encontrarlo, con muy buenas razones, en la contraposición original e insalvable entre intuición y concepto, entre lo dado por la sensibilidad y lo elaborado por el entendimiento. La radicalización de un dualismo es, para Hegel, síntoma de una ruptura que debe ser superada, precisamente porque viene a ser la señal de que un concepto fundamental ha desarrollado todas sus potencialidades y está en 
trance de elevarse a una síntesis superior. Cuando un momento histórico experimenta un desgarramiento profundo, es señal de que la hora de la reconciliación está cerca.

Sin embargo, el problema del dualismo kantiano no se restringía, como ya hemos podido ver, al campo epistemológico, sino que lo más grave del asunto lo veían los idealistas en sus repercusiones antropológicas. Porque el ser humano aparecía como una realidad radicalmente desgarrada, esquizofrénica, viviendo en dos mundos por completo heterogéneos, uno cognoscible, pero sometido a la más implacable necesidad mecánica, y otro abierto a la total libertad, pero incognoscible. Esta imagen del hombre se hallaba en consonancia con el problema que significaba para los románticos tratar de conciliar el impulso que lleva al ser humano a afirmarse a sí mismo (Selbstheit o mismidad), y el impulso que lo lleva a abrirse y entregarse a los demás (Liebe o amor). Y fue Hölderlin el primero que buscó darle una respuesta filosófica, es decir, estrictamente conceptual, al encontrar en la belleza y en el amor la superación de ese dualismo. Sin embargo, si esta idea pudo servirle a Hegel para tomar distancia de Kant, su natural desconfianza frente a las efusiones románticas lo orientó más bien en la dirección de Fichte, quien, como hemos tenido ocasión de verlo, buscaba un principio de unidad que fuera a la vez epistemológico y ético.

Sin embargo, bajo la influencia de Schelling, Hegel comprende la necesidad de concebir el Yo absoluto o incondicionado, no solo como una idea reguladora o como una meta inalcanzable, ya que ello no hacía sino trasladar la angustia humana desde un desgarramiento originario, tal como se hallaba en Kant, a un anhelo de perfección inalcanzable, a un deber ser irrealizable. Era necesario concebir ese Yo incondicionado como la realidad última, como la naturaleza misma de todo lo que existe. Pero no resultaba posible aceptar que el acceso a ese Yo absoluto solo puddiera lograrse, como pretendía Schelling, mediante la renuncia al conocimiento racional y la inmersión en lo Uno originario donde toda determinación desaparece.

Tanto la Fenomenología del espíritu como La ciencia de la lógica pueden ser consideradas como dos intentos complementarios de llevar a cabo una adecuada 'deducción trascendental de las categorías', pero no solamente de las categorías del entendimiento, sino igualmente de los conceptos de la razón. En otras palabras, no solamente de aquellos conceptos mediante 
los cuales nos es dado entender el mundo circundante, sino también de aquellos que nos permiten comprenderlo desde la perspectiva de la totalidad: sub specie eeternitatis, como había dicho Spinoza. La idea que subyace a esos dos escritos hegelianos es la misma: buscan mostrar cómo los conceptos mediante los cuales conocemos todo lo que nos es dado en su variada complejidad, si se los examina de manera adecuada, dan a conocer no solamente su peculiar insuficiencia y la necesidad de ir más allá de cada uno de ellos para "superarlos" (aufheben), sino que, ordenados de manera racional, nos llevan a comprender la necesidad de concebir la realidad misma como un Yo absoluto o incondicionado. Ese Yo, por su misma naturaleza, solo puede hacerse real en el despliegue de sí mismo fuera de sí, es decir, en la concreta y pasajera realidad sensible que percibimos; pero debe, a su vez, comprenderse a sí mismo como la racionalidad que rige ese devenir y le da sentido. Esta es, precisamente, la tarea que le corresponde a la filosofía: mostrar que la realidad es, en último término, un despliegue de la razón en la frágil y pasajera consistencia del mundo material.

Voy a terminar estas consideraciones con una esclarecedora cita de Dieter Henrich, en la que podemos ver la manera como Hegel, en su esfuerzo por ir más allá del criticismo kantiano, reinterpretó el principio fichteano del Yo incondicionado:

En efecto, el todo en relación al cual sucede toda oposición no es nuestra conciencia, ni tampoco ningún yo previo a todo el proceso de despliegue. Pero en su lugar ese todo, que existe únicamente como proceso y es por lo tanto el proceso mismo, no puede ser concebido sino como yoidad, y según la estructura de la subjetividad. Quien tacha al fichteanismo por su método, es quien precisamente comprende lo que significa la doctrina de Fichte. A su lado quería Hegel ser enterrado. (Henrich, 1987, p. 32). 